\title{
Aproximación fenomenológica a la razón mediadora de Zambrano. Intuición y creación 1
}

\section{(Phenomenological approach to the mediating reason of Zambrano. Intuition and Creation)}

\author{
Ma Carmen LÓPEZ SAÉNZ
}

Recibido: 15 de septiembre de 2012

Aceptado: 21 de febrero de 2013

\section{Resumen}

Este artículo estudia la razón de Zambrano desde sus albores como razón mediadora. Su rechazo del sistema va unido a su comienzo en la intuición y a su decurso temporal, que analizamos en relación con Bergson y Husserl. La razón poética va más allá de ese núcleo intuitivo para revelar re-flexivamente incluso lo invisible. Su inmersión en las profundidades, en la pasividad actuante, en las entrañas, en la multiplicidad de los tiempos es paralela a la fenomenología de la génesis merleau-pontiana, a su poiesis carnal e incluso al telos de una razón ampliada al sentir. Ambos filósofos ejercitan su nueva concepción de la filosofía en la existencia.

Palabras claves: Razón, intuición, fenomenología, vida, existencia.

\begin{abstract}
This article examines the Zambrano's reason from its beginnings as a mediating reason. Her rejection of the system is linked to its start in the intuition and to its temporary course, which we analyse in relation to Bergson. Poetic reason goes beyond that core intuitive in order to reveal re-flectively the invisible. His immersion in the depths, in the acting passivity, in the entrails, in the multiplicity of the times, is parallel to the merleau-pontinian phenomenology of the genesis, to his carnal poiesis
\end{abstract}

\footnotetext{
1 Trabajo realizado en el marco del Proyecto de investigación, FFI2012-32575.
} 
and even to the telos of an enlarged reason upon feeling. Both of them practise their new conception of philosophy in existence.

Keywords: Reason, Intuition, Phenomenology, Life, Existence.

\section{A la búsqueda de una razón más ancha: Merleau-Ponty y Zambrano}

Zambrano (1904-1991) fue coetánea de Merleau-Ponty (1908-1961). En sus obras nunca se citan, pero, leídas con detenimiento, revelan núcleos comunes que no sólo obedecen al momento histórico con el que se comprometieron, sino también a las filosofías desde las que pensaron la vida y marcaron sus propios "estilos"2. Nos centraremos aquí en la fenomenología.

Merleau-Ponty se adscribió tempranamente a ella, interesándose por los manuscritos husserlianos inéditos, desarrollando especialmente los temas de la génesis de la razón. Zambrano conocía esta corriente a través de sus maestros Ortega y Zubiri³. Fue especialmente sensible a la herencia de la misma reinterpretada éticamente por Scheler.

Como Ortega, se sintió atraída por la Lebensphilosophie de Dilthey y Bergson. Husserl discrepaba de la indefinición y el relativismo de esta filosofía de la vida; en cambio, Merleau-Ponty nunca cesó de pensar con Bergson.

Desde este horizonte, la razón zambraniana se manifiesta tendiendo puentes entre los aparentes opuestos: la interioridad de la persona y la exterioridad del personaje, lo individual y lo social, el sentir y el pensar. Esta razón mediadora concuerda con la razón merleau-pontiana que se va haciendo renunciando de iure y de facto a los dualismos clásicos.

Ambos filósofos comparten influencias y un gran número de temas, debido a la atmósfera que respiraban, a su concepción de la filosofía como actitud y ejercicio, a su crítica del positivismo y del intelectualismo, de la raquítica razón cartesiana y a su común deseo de ampliarla a todo lo que la precede y la excede; en primer lugar, a todas las pasividades que nos afectan y operan en nuestros actos ${ }^{4}$. El estudio de las mismas es clave para las descripciones zambranianas del nivel pático y para la fenomenología genética de Merleau-Ponty. Ponen de relieve ese otro lado de la vida que, a pesar de no ser una representación activa del yo, se manifiesta como horizon-

\footnotetext{
2 Entendemos el "estilo" fenomenológicamente: "estilo constante, con una ininterrumpida unidad de identidad, un carácter personal" (Husserl 1991, 1931, p. 101).

3 Sobre la fenomenología en Ortega, San Martín (2012); sobre la de Zubiri, Conill (1991, 2005) y Pintor-Ramos (1991).

4 De ahí uno de los fenómenos en los que Bergon, Husserl, Merleau-Ponty y Zambrano se han detenido: el sueño. Véase López (2013, pp. 21-83).
} 
te vital y actúa como fondo desde el que se destaca la racionalidad y al que debe remitir para no perder de vista sus raíces y límites. De ahí surge otro de los objetivos que estas filosofías comparten: la reivindicación de otra razón distinta de la establecida. Zambrano la denominará "razón mediadora" y "razón poética"; Merleau-Ponty, desde 1945, proclamará la unidad de la razón en la aisthesis 5 .

Zambrano confiesa haber descubierto tres modos de razón: la cotidiana, la mediadora, "que aparece en el prólogo de El pensamiento vivo de Séneca, y la razón poética, que siendo quizá la más generadora surge en un ensayo llamado 'Hacia un saber sobre el alma', que fue publicado en la Revista de Occidente" (1987a, p.71), en 1934. En la edición de 1986 del libro de 1950 en el que se recoge dicho ensayo, declara: "aparecen aquí, en su germinar, esas dos formas de razón -la mediadora y la poética- que han guiado todo mi filosofar" $\left(2008^{6}\right.$, p. 9). J. Moreno asegura que la razón mediadora se pone de manifiesto a la vez que las preocupaciones políticas zambranianas, entre 1928 y 1934 y que en 1965, se convierte ya en estricta razón poética (1996a, p. 148). En nuestra opinión, esta última no es sino una profundización de la razón mediadora que quiere ir más allá de la estrechez de la razón racionalista y también de la intuición directa que se cree autosuficiente.

Tal vez, al principio, Zambrano teme denominar abiertamente a la razón "poética", porque quiere hacer filosofía y la estricta mirada orteguiana le conmina a ello. Ahora bien, la razón mediadora tiene ya los rasgos de la poética, incluido el de la generación de algo más ancho que la pura razón, esa que es "pura monotonía" (1996a, p. 215). Su tarea consiste en mediar entre lo universal abstracto y lo singular concreto, entre la verdad y la vida, porque ésta necesita que aquélla le ayude a salir de su oscuridad sin deslumbrarla, buscando su articulación dentro de sí, en su apertura a la verdad (Cfr. Zambrano 1995, pp. 31-32).

Ya en su primer libro, Horizonte de Liberalismo, sospecha de la razón dominante, sobre todo, porque se cree eterna y sólo considera digno de ella lo que se sustrae al tiempo. Esa razón tiene como finalidad "embalsar la corriente del tiempo (...) y levantar su castillo ideológico sobre los descarnados, óseos, cimientos de lo ideal, de lo supratemporal, desdeñando el humilde limo terrestre, donde el fermento del tiempo hace germinar la vida" (Zambrano 1996a, p. 212).

El racionalismo a-temporal estanca, en lugar de encauzar6. Así, no sólo no da cuenta de la vida, sino que se evade de ella, pues la vida es continua gestación en el seno del tiempo, desde el "limo terrestre". Este légamo despreciado por el racionalismo, enlaza con la afirmación merleau-pontiana de que "la sedimentación es el único modo de ser de la idealidad" (1964, p. 288), porque las ideas van cuajando

\footnotetext{
5 Véase López (2003) y (2010a). La razón zambraniana media entre la pasividad la actividad que late ya en lo sensible (Cfr. Zambrano M-462, 9/9/1958. Cit. por Balza, 2000, p. 70).

${ }^{6}$ Cfr. J. Moreno repara en esta diferencia que la autora toma de su padre (1996, p. 185).
} 
con el tiempo y depositándose en la historia. Si tienen alguna eternidad, arranca de su temporalidad.

Para ambos filósofos, verdad y temporalidad se dan conjuntamente, experimentando retrocesos y anticipaciones. La realidad es este flujo y no el remanso en el que se instala la mirada instantánea. Zambrano denomina "real" justamente a eso que participa de la verdad y del tiempo; Merleau-Ponty comparte este interés por un "universal existencial"7 que parte de lo concreto, pero no con objeto de permanecer en él, sino de profundizar hasta descubrir aquello de lo que toda particularidad participa diversificándose.

Entre lo singular y lo universal media la razón poética, que asume la razón vital de Ortega y la sentiente de Zubiri, yendo más allá de la razón histórica, ya que revela procesos más existenciales y necesarios para ser completamente. Con esto no queremos decir que la filósofa desprecie la historia, pues, como declara, el tiempo forma parte de todo lo real y la dimensión temporal es la "inevitable hija" (2011d, p. 155) de la historia. La biografía y la obra de Zambrano, como la de MerleauPonty, están marcadas por su propia historia, como se revela en su compromiso humano y sociopolítico; asimismo, llevan la huella de la esperanza -no ingenua, sino reflexiva y crítica- en una razón que salve al ser humano de su existencia escindida y lo recree como persona.

Zambrano es consciente de que la razón se nutre del suelo mundano vital y que se va ensanchando a medida que comprende las insuficiencias de la razón establecida para dilucidarlo. La sabiduría que arroja la nueva razón no es la del saber absoluto de lo universal y necesario, sino ese saber vivir aceptando que somos hijos de Poros y Penia, un saber "que en cada instante de la vida, para cada asunto y circunstancia, existe una cierta mezcla de razón y sinrazón, de ley y desorden" (Zambrano $1992^{2}$, p. 31), porque el saber no es una ocupación de la mente sino un ejercicio que transforma el alma entera. Ésta era, para Ortega, la instancia mediadora entre la vitalidad y el espíritu -integrantes de la intimidad humana-; albergaba los sentimientos, emociones, deseos, apetitos. Ella recoge el testigo y concibe el alma como conjunción entre el cuerpo y la conciencia, como lo que precede al conocimiento, sede de la intimidad del sujeto y de su apertura a la exterioridad. El saber sobre 8 la misma aprehenderá el vínculo de la realidad dada con la que nos atañe, eso que la fenomenología denominará "sentido", un saber para vivir coexistiendo, transformando y proyectando.

\footnotetext{
7 Merleau-Ponty llega a este universal concreto compaginando el análisis estructural con la descripción de la experiencia vivida. Véase López (2012a).

${ }^{8}$ Se trata de un saber edificado "sobre" el alma que repercute en ella, no de un conocimiento metódico de un objeto acotado, porque Zambrano, como heredera de la lucha husserliana contra el psicologismo, no concibe la psique como un contenedor de "objetos" psíquicos.
} 
Estos cometidos son filosóficos, porque no se limitan a expresar intuiciones, sino que reflexionan sobre ellas y las transmiten. Nos muestran otro modo de hacer filosofía que no conoce atajos ni elude compromisos.

\section{El punto de partida: la intuición}

Zambrano, como Bergson, busca el sentido de la vida renunciando al sistema que uniformiza lo diverso e inmoviliza lo que es móvil. Husserl, por su parte, nunca fue sistemático; ${ }^{9}$ jamás dio sus obras por concluidas, sino que las consideró como introducciones a la fenomenología. Ésta es una corriente teórico-práctica, es decir, se va haciendo a la vez que se tematiza. Como dice Waldenfels, "no permite que sistemas, escuelas y disciplinas le arranquen el estímulo del cuestionamiento y de la investigación de objetivos. Para su fundador siempre se trató de una 'filosofía de trabajo"” (1997, p.11).

Zambrano evitaba el sistema por su inadecuación para la vida. Pensaba que en el origen de cualquier sistema siempre había alguna intuición. Ésta es el punto de partida de las filosofías que abordamos. No se dirigen a la intuición para acceder a las ideas, ni a la subjetividad; tampoco para quedarse en la pura contemplación o en el activismo puro. No la identifican con la aprehensión directa de un principio del que todo se dedujera. Tan sólo hace converger líneas de hechos sin imponerles un orden, explicitando su sucesión, escuchando y acogiendo su revelación.

De acuerdo con Bergson, la intuición no es un método más, sino la filosofía misma que capta sin detenerlo el movimiento y la riqueza de lo viviente. La intuición aprehende la individualidad de las cosas que escapa a la percepción común que se concentra en las impresiones útiles para la acción.

Zambrano parte de la intuición cotidiana que es reveladora y nos afecta, que delata el mundo oscuro y silencioso en el que no teme profundizar. No se adentra en ella de modo impositivo, sino receptivo. De ahí su preferencia por el fragmento que recoge el momento intuitivo, frente al sistema deductivo que ordena y simplifica la realidad.

Como para su predecesor, la intuición no es tanto ver con el ojo, sino con el espíritu que, especialmente en Zambrano, siente con las entrañas, con ese impulso que se dirige al fondo padeciendo con él sin anular su misterio. Esta senda es similar a la bergsoniana intuitus mentis: «Llamamos intuición a la simpatía por la que nos trasladamos al interior de un objeto para coincidir con lo que tiene de único y en consecuencia de inexpresable» (1984b, p. 1395).

\footnotetext{
${ }_{9}$ Zambrano reconoce en la gran influencia de Husserl sobre Ortega, a pesar de que éste criticara la ausencia de unidad y sistema de aquél (Cfr. "Conferencia de San Juan de Puerto Rico sobre Ortega y Gasset”, en Tejada 2011, pp. 247-268, 255, 257).
} 
Merleau-Ponty prefiere hablar de Einfühlung (1964, p. 302) entre el perceptor y lo percibido, para captar el ser in-objetivo que somos, la chair (carne).

La inteligencia abstracta no puede intuir así, ya que analiza y disecciona. Sin embargo, los tres filósofos consideran que inteligencia e intuición se comunican en toda experiencia. No es que Zambrano renuncie al orden y al concepto, sino que, como Bergson, piensa que hay que invertir su curso ${ }^{10}$ y comenzar por la de la realidad radical que es la vida. La filosofía no puede evitar categorizarla porque quiere comprenderla, pero debe ser consciente de que los conceptos, que olvidan su procedencia, la coagulan. La intuición, en cambio, es "la realidad siempre renovada frente a las inmóviles ideas" (Zambrano 1996a, p. 226).

Husserl también se dirigió a la intuición para alcanzar "las cosas mismas", y la evidencia de que lo dado es realmente lo mentado por las significaciones de las palabras (Cfr. 1984a, p. 10). Los conceptos lógicos tienen que tener su origen en ella si quieren ser unidades válidas de pensamiento. Además de la intuición sensible de lo individual, desarrolló la intuición eidética, captadora de esencias, y su equivalente, la intuición categorial. 11

Aunque la intuición de las esencias es ajena a Bergson, la intuición fenomenológica se aproxima a la bergsoniana en tanto que ambas son visiones directas de algo que no es mera sustancia positivizada, sino dato inmediato de la conciencia que fluye con ella. Zambrano considera precisamente que lo que une a Bergson con Husserl es que parten de esta conciencia fluyente unida a la vida. 12

Bergson identificaba la intuición con la filosofía; Husserl la adscribe a la razón, haciendo frente a la crítica especulativa que rechaza la intuición intelectual y somete la sensible al entendimiento:

La razón es conocimiento intuitivo, y se propone, precisamente elevar el entendimiento a la razón (...). Por lo tanto, lo menos posible de entendimiento, pero lo más posible de intuición pura. Intuitio sine comprehensione. Nos viene, en efecto, a la memoria el lenguaje de los místicos cuando describen la intuición intelectual, que no es ningún saber de entendimiento. Y todo el arte consiste en dejar la palabra puramente al ojo que ve y desconectar el mentar (Husserl 1973, p. 62).

La razón es intuición, visión directa similar a la experiencia mística que impactó en Bergson y en Zambrano. Ésta asegura que los filósofos contemporáneos que han reconocido las estrecheces de la razón y se han propuesto ampliarla, han teni-

\footnotetext{
10 «Ir de la realidad a los conceptos y no ya de los conceptos a la realidad» (Bergson 1984a, pp. 14151416). Zambrano todavía va más allá de los conceptos a su concepción en el sentir.

11 En la VI de las Investigaciones Lógicas se estudia esta última (Cfr. 1984b).

12 Cfr. Zambrano, "Conferencia de San Juan de Puerto Rico sobre Ortega y Gasset", en Op. Cit., p. 253).
} 
do presente la mística; no menciona a Husserl, ni siquiera su última obra en la que acusa la crisis de la racionalidad de las ciencias europeas; en cambio, alude a Bergson (Cfr. Zambrano 1975, p. 3). Los tres consideran que la razón de la experiencia es intuitiva más que constructiva; va a la inmediatez de la vida y permite ver sin deformaciones, pero también hacer ver lo que no percibimos de modo directo.

Cada experiencia es, para Zambrano, un claro en el bosque, un despejar pasivo e inmediato que requiere una confianza en el padecer, una "claridad aleteante que apenas deja dibujarse algo que al par se desdibuja" (2011d, p. 123). La inmediatez del saber que se produce en los claros se debe a su revelación inmotivada. La razón poética nos abre a ellos ensanchándose hasta recoger las experiencias místicas. Al tratarse de experiencias, la fenomenología no renuncia a ellas, sino que las toma, como se puede apreciar en el fragmento de Husserl, como prototipos de aprehensión por intuición inmediata, una vez hecha epojé13 de la teorización.

La intuición es, para Zambrano, lucidez y saber. Así opera también la intuición bergsoniana, la cual lo es, ante todo, de la duración, de la realidad. La especialización intelectual olvida el carácter originario de la intuición, el que "nos hace conscientes de nuestra libertad y nos permite alcanzar el élan vital que es fuerza evolutiva creadora. La intuición de la que hablamos lleva, ante todo, a la duración interior" (Bergson 1984a, pp. 1272-1273), a un crecimiento desde dentro, a la visión inmediata del espíritu por el espíritu o, en términos fenomenológicos, a la inmanencia de la conciencia. Ésta sólo es uno de los polos de la intencionalidad, ausente en la conciencia bergsoniana y, en cambio, asimilada por Zambrano a la atención, entendida como posesión inmediata "como por adelantado"14 de la realidad. Zambrano la halla en el inicio y como fundamento del método fenomenológico, aunque, a diferencia de Husserl y Ortega, es la vivencia misma, en su prolongada atención, la que desata su referencia a la realidad, es decir, el sentir-del que jamás puede hacerse epojé- es el motor de la intención, que es deseo: "el ser se nos da en el sentir, "en su entraña"' (2011b, p. 893). Después, se ha de penetrar intuitivamente en tal resistencia.

Zambrano reconoce la dificultad de expresar la inmediatez (Cfr. 2011d, p. 14) intuitiva que es fundamental para el saber, aunque el pensar metódico la haya erradicado. Este saber pasivo y revelador con el que se inicia todo conocimiento sólo podrá ser recuperado por la vía de la razón poética.

\footnotetext{
13 Sobre la consideración de este procedimiento fenomenológico por Zambrano, véase López (2013, pp. 26-27).

14 Zambrano, "Esencia y forma de la atención”, cit. en Moreno (2008a, p. 356).
} 


\section{Razones del corazón e intuición de la duración}

El corazón es el órgano de ese saber inmediato y pasivo, del ritmo sin discontinuidades, del movimiento de la vida que nutre todo conocimiento y a la que éste se debe. Ese lugar original del hombre tiene también sus razones, que no son las del racionalismo, pues su función principal es pensar el sentir originario del que brota todo pensamiento y todo padecimiento. Las razones cordiales, que han sido colonizadas por la razón unidimensional dominante, pero son imperiosas para la vida, serán acogidas por la razón zambraniana.

Merleau-Ponty conviene en la recuperación de la razón de su potencial poiético que, unido a su dimensión aisthética ${ }^{15}$, la harían apta para descifrar lo que se siente y adentrarse en esa verdad, de camino a la realidad, que pasa por la reinvención de la sensibilidad y desemboca en una razón sensible y sentiente. El fenomenólogo la denominará abiertamente carne. 16

La razón sentiente de Zubiri será la que recoja Zambrano; esta razón no sólo ilumina lo externo, sino también lo interno, las entrañas que son sede del sentimiento, anteriores al logos. Su clarificación es imprescindible para que vida y conocimiento marchen a la par. Sólo así la razón será capaz de aprehender una verdad que nos implica o, como dice Zambrano, que enamora. Esta verdad no queda al arbitrio de la voluntad; se busca y se encuentra, aunque no se quiera, y la filosofía que se rinde a ella es un saber sobre el alma que ordena nuestro interior mientras vivimos y produce, así, un conocimiento íntimo. Zambrano no está defendiendo aquí algún tipo de sentimentalismo, sino recuperando el significado de la «filosofía», en tanto amor por la sabiduría de las cosas profundas. Esto puede parecer una utopía para los seres temporales que tienen que detener el fluir para pensarlo, pero se convierte en el telos de quienes aceptan que no hay conocimiento absoluto, sino un saber marcado por el ordo amoris. La raíz de éste se halla en el ser carnal y viviente del corazón que habita en la profundidad, en "ese espacio que sentimos crearse" (Zambrano 20086, p. 68) y del que no somos hacedores.

Merleau-Ponty dice, además, que en la profundidad elaboramos nuestro medio (Cfr. 1979, p. 326). No es la tercera dimensión, sino la primera, la dimensionalidad que hace que las cosas tengan "carne", es decir, densidad y relación. En la profundidad del mundo sensible, en su espesor, se encuentran las esencias (Cfr. 1964, 273), entendidas como lo invisible de lo visible. La profundidad contribuye a «crear un nuevo tipo de inteligibilidad» (Ibídem, p. 322) que no es la de un sujeto distan-

15 Zambrano, como Merleau-Ponty, denuncian el confinamiento de esta dimensión fundamental a la sola sensibilidad. Véase López (2010a).

16 Sobre este concepto clave de la nueva ontología merleau-pontiana, su carácter sensible-sentiente, véase López (2007d). 
te y radicalmente opuesto a los objetos, sino la que le corresponde a una razón integradora y estesiológica.

De la misma manera que la profundidad merleau-pontiana habita la carne imbricando al sentiente y al sensible, el corazón zambraniano convierte en entrañable todo lo que anida en él; debido a ello está presente en toda respuesta personal (Cfr. Zambrano 1989b, p. 111), es el centro de realización del ser humano, «matriz originaria de la vida del sentir» (Cfr. 1989c, p. 16), paradigma de una activa pasividad (Cfr. 20086, p. 66) y de una piedad acogedora. Esta víscera media entre las entrañas y el logos: es un centro que palpita y sostiene antes de ver algo ( $C f r$. Zambrano 2011d, p. 141). Con su escucha comienza el saber zambraniano sobre el alma.

Merleau-ponty emplea términos como "matriz", "pregnancia", para referirse a la carne, como nivel pasivo de significaciones, no constituido por la conciencia, que se anuncia en todos los actos. Defiende una pasividad sin pasivismo ( $C f r$. 2003, p. 159), es decir, asumida y, por consiguiente, no absoluta.

Como él, Zambrano recupera la pasividad generadora de la carne y alude a la condición mediadora de misma ( $C f r$. 2011d, p. 265) entre la vida y la muerte, la gestación y la extinción. Convienen en que la vida del sentir que arranca de ella no es el conjunto de sentimientos, entendidos como transformaciones de lo sentido en posesiones intelectuales, sino la experiencia vivida de la reversibilidad entre sentirse sentido (pasividad) y, a la vez, sentiente (actividad). Zambrano llega a ella cuando intenta algo vedado a la filosofía e incluso a todo pensamiento: describir el tiempo naciente. Entonces, se aproxima a un ser in-objetivo y a-subjetivo que, a pesar de ello, se manifiesta:

Presencia que no se exterioriza, dentro y fuera del que así lo siente despertando y que no pide ni ofrece ni tampoco se niega a ser vista. Pues que se la siente al par que uno mismo desde lo hondo se siente. Un sentir y un sentirse recogidamente (Ibídem, p. 141).

Ambos comprenden el sentir17 como afección y acción. Consideran el corazón no sólo como su "órgano", sino, incluso, como centro del pensar viviente. MerleauPonty toma su latido por pasividad actuante que no necesita de un yo: «no soy yo lo que me hace pensar como tampoco soy yo quien hace latir mi corazón» (1964, p. 275).

Reconduce pensamiento y vida a su nacimiento, el cual es un desafío para la fenomenología de la constitución, pero un acontecimiento radical para la existencia. De ahí que ambos se hayan detenido en esos fenómenos que no son producidos por el yo activamente, pero que le afectan; el más destacado, el tiempo.

\footnotetext{
17 Sobre la común fillosofía del sentir de Merleau-Ponty y Zambrano, López (2013, principalmente pp. 83-137).
} 
Zambrano estudia sus múltiples formas. Denomina "duración" a la primera de ellas. La define como "receptáculo y molde" (2011b, p. 885) del tiempo que fluye, como un cauce de éste carente de movimiento espontáneo, homogéneo, mero pasar monótonamente (Cfr. Ibídem, p. 887). Esta duración no es la durée de Bergson ${ }^{18}$, en la que se fusionan forma y contenido, de modo que cada participación en ella se siente cualitativamente distinta; todo lo contrario de lo que ocurre con la homogeneidad de esta forma del tiempo zambraniana. Ambas, no obstante, son datos verdaderos e inmediatos de la conciencia, a diferencia del tiempo objetivo, que sólo es aparente.

Zambrano se adhiere a la crítica bergsoniana de este tiempo cuantitativo y homogéneo que no es el tiempo de la vida: "La vida es el discurrir del tiempo. Y esta temporalidad de la vida queda mutilada si el racionalismo absolutiza la presencia, es decir, el presente, prescindiendo del discurrir, sub specie aeternitatis" (1989b, pp. 98-99). Según la autora, Husserl formaría parte de esa metafísica racionalista (Cfr. 1989b, pp. 81-82).

Bergson, por el contrario, alentaba a mudar esta perspectiva reduccionista y a percibir la eternidad de vida "sub specie durationis" es decir, no como una eternidad de inmutabilidad o un presente repetitivo, sino como eternidad de vida, o presente espeso, elástico, dilatado hacia el pasado que le imprime su élan. Así la vida nos vivifica y su intuición "nos da la alegría" (1984a, p. 1392). Zambrano caracteriza de modo similar la realidad: "Se extiende como un presente, en una estabilidad en movimiento" (1987c, p. 110).

Intuida de este modo la temporalidad originaria, podemos concebir el tiempo, tener identidad, posibilidad de recrearla y de crear, porque lo que dura no es un estado inmodificable, sino la continua transición de la existencia. En la duración tienen lugar la identidad y las diferencias, dado que es continuación de lo que ya no es en lo que es, "continuidad indivisible de cambio" (Bergson 1984a, p. 1384), "una memoria interior al propio cambio" (Bergson 1992, p. 41) y no la presentificación de lo que fue.

Aunque Zambrano se opone a ésta, evita circunscribir la temporalidad en la memoria. Más cerca de la fenomenología, la considera como un primer modo de la presencia y como una síntesis pasiva, a la manera de la conciencia interna del tiempo o de la sedimentación del sentido. Discrepa, no obstante, de la retención husserliana que es reintegrada en el presente de la conciencia, sin percibir que, en Husserl, el tiempo de ésta no es lineal, sino una red de presentaciones, retenciones y protenciones.

Zambrano no niega el tiempo sucesivo de la conciencia, sino que rescata otros tiempos encubiertos por él; a ello se dirige su fenomenología del sueño. Pretende

18 Sobre la comprensión zambraniana de la durée, López (2013, pp. 36ss, 73ss). 
convertir el tiempo de la conciencia en un tiempo mediador, es decir, en un presente dilatado hacia el pasado y hacia el futuro; entonces, la memoria deja de ser una obsesión o una monotonía y se transforma en "arte y sabiduría del tiempo" (Zambrano 1987b, p. 124) que ampara el renacer del sentir y la libertad. Como para la fenomenología, ésta, que es la responsable de las síntesis activas, debe prevalecer en la vida humana, la cual es vida despierta, esfuerzo por querer y entender.

La razón poiética se encuentra con ese fluir vital desde dentro, no se impone sobre él, sino que es la mensajera de la vida misma que se gesta con ella, que la exige, porque la vida no es dejarse vivir, sino un continuo hacerse orientado por el deseo y por la tensión creadora. La vida "es algo que se gana (...) algo que por minúsculo que sea es creación, y, por serlo, sigue creando y se perpetúa" (Zambrano 2011c, p. 460). Esta determinación esperanzadora hacia el futuro -no hacia el previsible porvenir- contrasta con la que en Bergson detenta el pasado, pero la influencia de La evolución creadora es evidente en la filósofa.

La conciencia que intuye la duración conserva todo para crear, madurar, cambiar, hacerse indefinidamente en la propia duración (Cfr. Bergson 1984c, p. 496). Su duración es creación, porque está en movimiento, pero, además, es libertad porque no pertenece a la materia inerte, sino a la vida ( $C f r$. Ibidem, p. 782).

Así entiende también Zambrano la vida, como eso que no permite reposo, aunque sentencia que "la vida no dura, no permanece, se hace" (Cfr. Zambrano 2011c, p. 462). Desde su primera obra, saluda la idea de la evolución y la recomienda en política (Cfr. 1996a, p. 220), porque no sólo tiene lugar en la naturaleza, sino que es "la esencia de lo humano" (Ibidem, p. 228) y la razón la asume en su fuerza poiética. Las coincidencias de ésta con el élan vital bergsoniano que impulsa a la intuición, son innegables, a pesar de que la primera disipa cualquier sospecha de biologismo subrayando el papel de la actividad humana.

La intuición de la duración es, como en Bergson, el fondo continuo de todo fenómeno, pero, a diferencia de él, no es la interioridad de la realidad, sino sólo uno de los tiempos del sujeto, concretamente la atemporalidad del que duerme. Para que el tiempo sucesivo emerja de ella es necesario establecer cierta discontinuidad, la misma que nos hace tomar conciencia de la continuidad. En este sentido, consideramos que haría suya la crítica que Merleau-Ponty dirige a la durée bergsoniana: tiene razón en su denuncia de la espacialización del tiempo, pero no llega a una "auténtica intuición del tiempo" (1979, p. 475), ya que hace "bola de nieve consigo misma", es sucesión indiferenciada.

Se ha dicho que la intuición bergsoniana es la perfecta coincidencia de la duración consigo misma, sin ninguna mediación expresiva ( $C f r$. Caeymaex 2005, p. 86). De esta total coincidencia se seguiría que la filosofía no se distancia de lo que no es filosofía. Zambrano parece incurrir en ella cuando identifica la conciencia natural con la reflexiva y declara innecesarias la epojé y la reducción fenomenológicas 
(Cfr. 2011b, pp. 845, 847). Sin embargo, insiste en la necesidad de la filosofía para clarificar la realidad en todas sus dimensiones, incluidas las recónditas, esas que suspenden por sí mismas el decurso de la vida consciente. Esta suspensión caracteriza la actitud fenomenológica; en Zambrano se traduce en la necesidad de aprender a mirar; 19 esto puede considerarse ya un modo de epojé del mero ver y una intención de trascender lo que en la aptitud natural damos por sentado. No está, por tanto, lejos de la reflexión, entendida como "percepción intuyente" (Cfr. Husserl 1976, p. 95).

Si Husserl proclama la necesidad de pasar de la actitud natural a la fenomenológica, es para asumirla esclareciéndola. No se trata de mantener tal y como es lo pre-reflexivo, tampoco de suprimirlo, sino de entender su carácter fundante de la conciencia, debido a que, a su vez, está fundado en ella: es su suelo nutricio, pero únicamente por la reflexión se hace manifiesto; como Merleau-Ponty dice, "reflexionar, entonces, es desvelar lo irreflexivo" (1995, p. 108), realizar en éste la razón, la cual se torna creadora cuando reconoce la parcialidad de lo fáctico y se remonta a lo originario, al germen del logos. Merleau-Ponty declara haber aprendido del último Husserl, que reflexionar no es otra cosa que desvelar ese logos tácito (Ibídem, p.104).

La misma Zambrano se da cuenta del clamor desde dentro de la razón de un «logos sumergido» (1989b, p.130) del sentir de la vida que se entrega en un lenguaje indirecto y simbólico y cuya pasividad nos determina.

La fenomenología genética nos conduce a esa dimensión, todavía no tematizada, de la que procede la pasividad originaria, que es el trampolín de la conciencia. También la intuición bergsoniana tal y como la entiende Merleau-Ponty: no sólo como captación directa, sino como lo que nos enseña a ver, ya que actúa como una cierta "reducción" de todas las cosas sub specie durationis (1960, p. 232). Por eso, los conceptos han de revestirse de duración.

El fenomenólogo va todavía más allá, hasta la reversibilidad de la carne como multiplicidad infinita de la latencia y generación de toda diferencia. Gracias al horizonte carnal compartido, lo visible comunica con lo vidente, pero, asimismo, la profundidad de la carne instituye una distancia por la que se revelan las cosas mismas (Cfr. Merleau-Ponty 1964, p. 178), distancia en la proximidad.

Así entendida la re(con)ducción de la mirada fenomenológica y de la intuición bergsoniana de la duración es acorde con la zambraniana. Ciertamente, ésta descarta la reducción fenomenológica al ver desinteresado del sujeto trascendental, pero no tendría inconveniente en entenderla merleau-pontianamente como un desaprender a ver para poder mirar las profundidades con el ojo y el espíritu hasta tomar con-

\footnotetext{
19 Como Ortega, Zambrano distingue el ver del mirar; éste atiende al horizonte y a lo que no se ve, en suma, es conciencia de la reversibilidad entre lo latente y lo patente (Cfr. Ortega 1981, p. 36). El primer libro de Zambrano está dedicado a su padre porque le enseñó a mirar.
} 
ciencia de sus insuficiencias y erigir como paradigma una mirada que surge de la noche y de la historia, que no va a la caza: la de la razón auroral, capaz de reunir el instante con lo que perdura (Cfr. Zambrano 1986, p. 35) y de anticipar lo que todavía no es. Esta mirada que se despereza con los primeros rayos y, a la vez, abre el círculo de la aurora, responde a la misma inquietud que la intuición de la duración (Bergson) y la conciencia interna del tiempo de lo intuido (Husserl). Como ellos, Zambrano no se queda en la visión instantánea, sino que penetra reflexiva, aunque no deductivamente, en esos lugares y temas escasamente manifiestos para que reciban algún destello, mientras ayudan a la razón a constatar sus limitaciones ${ }^{20} \mathrm{y}$, consecuentemente, su necesidad de extenderse a todo eso que ha sido excluido de ella. Así es como la razón comprende que ha de redefinirse: abriéndose a lo otro de sí para entender la instrumentalización de la que ha sido objeto y las posibilidades que se le han cercenado.

\section{La actitud filosófica}

La actitud filosófica es imprescindible para pensar la vida; adoptarla es poner discontinuidad en ella, retraerse del ver y aprender a mirar.

Los filósofos aquí tratados convienen en que la ciencia no adopta esta actitud: no es intuitiva, sino que parte de conceptos "y no puede encontrar una realidad diferente con la mirada que va a buscarla" (Zambrano 1994, 1950, p. 27). En cambio, la intuición bergsoniana "desciende bajo las ideas a lo que hace que las haya, no a la conciencia solamente, sino a lo que engendra la conciencia: a la vida" (Ibídem, p. 28). La filósofa observa idéntica tendencia en Husserl: quiere hacer de la filosofía una ciencia renovada y estricta, abandonando los conceptos y empezando "por el simple contacto con las cosas, por la entrega ante la realidad" (Ibídem). También Ortega critica la razón pura en nombre de otra histórica. Zambrano se une a ellos en esa detracción de la razón artificiosa y en la defensa de otra generada en la vida, capaz de intuir algo en su génesis, que es "conocerlo en su intimidad" (Ibídem, p. 29). Para ello, es necesaria la actitud filosófica, que Zambrano describe como una retirada de las construcciones filosóficas "para hacer visible" lo más real (Ibídem) y ganar profundidad.

Esta "retirada" es análoga a la Rückfrage husserliana por el sentido de lo originario. Consiste en retroceder hasta crear un lugar propio desde el que percibir; es decir, la retracción genera nueva actividad; ésta última resulta necesaria para refle-

\footnotetext{
20 La conciencia de los límites de la razón es condición para ejercerla trascendiéndolos. En este sentido, Zambrano denomina a la razón que Séneca encarna "restringida" por las circunstancias; justamente por ellas, es "mediación” y "consuelo" (Cfr. 19922, p. 23).
} 
xionar sobre lo sedimentado (Husserl) y para volver a la realidad expresándola de un modo creador (Zambrano). Como ella, Husserl describió la actitud reflexiva o fenomenológica que va a las cosas mismas como una retirada de su consideración superficial. Empleó, para ello, la epojé y la reducción. La intuición fenomenológica que les sigue es el acto de la conciencia, no el de la experiencia naturalista que caracteriza a la ciencia. La crítica fenomenológica del objetivismo desencadenado por el privilegio de ésta no es ajena a Zambrano. ${ }^{21}$ Por otra parte, no debemos olvidar que la fenomenología estática de la conciencia es complementaria de una fenomenología genética cuyo tema es la génesis de la constitución, entendida como relación de la subjetividad con el mundo pre-dado, la génesis en la pasividad y su relación esencial con la actividad.

La filosofía bergsoniana es, asimismo, un saber de la génesis. Su intuición prepara la reflexión filosófica en tanto rompe con la "actitud natural" de la vida práctica. Como su coetáneo, Bergson se propuso establecer un método riguroso para pasar de ella a la reflexión filosófica. Comienza por "buscar la experiencia en su fuente", no en relación con nuestra utilidad, así "restableceremos la intuición en su pureza primera y retomaremos contacto con lo real" (1984d, p. 321). Esto exige un esfuerzo que rompa con las ideas preconcebidas y los hábitos adquiridos hasta llegar a la experiencia inmediata de la duración, la vida dinámica del espíritu ¿Qué otra cosa es la exención fenomenológica de prejuicios a la que apela la actitud fenomenológica? En el sentido de la misma, dirá Merleau-Ponty que la percepción de la duración nos enseña a ver de una manera nueva y es el principio de cierta "reducción bergsoniana" (1960, p. 299).

En Zambrano prevalece la integración, al menos por lo que se refiere al saber. A él llegamos - dice- de muchas maneras, "por observación aislada, por intuición, por inspiración poética, por esa iluminación repentina de la mente que capta algo de modo deslumbrador" (2005, p. 95). Este saber es pasivo e inmediato, como la intuición, ya sea sensible o inteligible. Difiere del pensar filosófico en que éste es activo, quiere ser saber legítimo y recurre al sistema. Zambrano es crítica del sistematismo, es decir, de esa modalidad que sólo considera válido lo que se rinde al sistema; sin embargo, acepta la salvación de otras modalidades para articular el pensamiento (Cfr. 1966, p. 115). Sólo así el saber tendrá orden y el pensamiento no eliminará saberes enriquecedores a costa de presumibles certezas.

La razón zambraniana media, pues, entre saber y pensar para humanizar creativamente el último, "que revela al hombre lo que es; le hace nacer." (Ibídem, p. 96), rescata su libertad y se dirige al futuro, mientras que las sabidurías se reciben del pasado. El pensar zambraniano es, por esa direccionalidad, camino por el que tran-

$21 \mathrm{~J}$. Moreno afirma que Zambrano era conocedora de las conferencias de Husserl sobre la crisis europea (2008a, p. 361). 
sitamos escuchando otros saberes. A nuestro modo de ver, éstos se sedimentan en tradiciones que han sido fundadas por el pensar y que, para ser fundantes, deben reactivarse hasta generar nuevos pensamientos.

Al igual que para Husserl, el saber acumulado es necesario, pero no suficiente para filosofar; es preciso, además reactivarlo desde la pregunta que le dio origen y desde la nueva situación de quien filosofa en singular:

Hay filosofía porque el saber no basta (frente a la tradición) todo saber es tradicional y se hace opaco o se oculta.

Cada filósofo revela la esencia de la filosofía. La hace existir aun en el sentido de Ortega existir resistir ser real.22

Como en Merleau-Ponty, la esencia sólo existe en las singularidades que participan de ella, y de un modo teórico-práctico. Zambrano se adhiere a la concepción existencial de las esencias y, como el filósofo francés define el existir como el movimiento de su actualización (Cfr. p. 2011a, p. 1034) resistiendo y la forma más humana de hacerlo es pidiendo razones.

\section{El ejercicio de la filosofía en la existencia}

La actitud filosófica es sólo en paso necesario para su ejercicio en la existencia, que requiere la ampliación de la razón al sentir y el compromiso con los otros en el mundo. Así lo entiende Zambrano de acuerdo con la fenomenología de la existencia. Apuntemos, en primer lugar, las resonancias en una de ellas eminentemente ética, la de Lévinas. Este fenomenólogo crítico del saber epistémico, define así su posición: "El sentir no es una forma vacía de conocimiento, sino una fascinación, una exposición a la difusa amenaza de la hechicería, presencia en un clima, en la noche del ser que acecha y atemoriza, y no presencia frente a las cosas" (1991, p. 62).

Tras valorar positivamente la "ruina de la representación" llevada a cabo por la fenomenología y Bergson, Lévinas aprehende la intencionalidad como apertura a un nuevo tipo de acontecimientos desplegados bajo la superficie que revelan el "drama" de existir; éste deviene un verbo transitivo y reflexivo a la vez, (como sentir y sentirse), porque la suya no es una reflexión teóretica, "sino un acontecimiento del existir mismo; no es una conciencia, sino un compromiso, una manera de ser cualificada por todas las circunstancias que habríamos estado tentados de tomar por decorados" (Ibídem, p. 66).

22 M. Zambrano. "Apéndices de la razón que se busca (A propósito de la razón vital)”, en Tejada (2011, pp. 278-279). 
En un sentido similar, hablamos de re-flexión para referirnos a la interrogación merleau-pontiana por lo pre-reflexivo. Algo parecido significa la llamada orteguiana a salvar las circunstancias. Zambrano se responsabiliza también de ellas, pero teniendo en cuenta que «la situación efectiva del hombre es padecer y trascender, y no sólo padecer, sino padecerse; soportar la carga de su pasividad» $(2011 \mathrm{~b}, \mathrm{pp} .851$ 852); es decir, el padecer no es determinismo de las circunstancias e inactividad, pues se manifiesta provocando un padecimiento en el sujeto humano, que realiza y siente lo que padece, y el sentir es «un sentirse como un pulso que sondea las cosas del otro lado» (1989b, p. 130), una alternancia de pasividad y actividad: «aquello que sucede fatalmente puede suceder luego activamente, aquello que el hombre padece es ejecutado por él» (2011b, p. 857).

En Merleau-Ponty, las circunstancias forman parte de la situación del existente, no "como un decorado", sino como lo que se siente. Éste no es mera pasividad, sino sentirse objeto y sujeto, hasta el punto de que la reversibilidad inminente de ambos acaba por mitigar cualquier padecimiento. Frente a la clásica asociación del cuerpo con el padecer y de la conciencia con el actuar, el filósofo que huyó de los dualismos no cesa de insistir en la unidad del cuerpo vivido en el que el papel jugado se transforma en sufrido.

De la ruptura de esa unidad originaria proviene, según él, la crisis de la razón. Su propuesta es ampliarla a todo aquello que la precede y la excede (Cfr. 1960, p. 154) para que contenga incluso lo que se ha considerado irracional y ha sido condenado al silencio. Confía en una razón que se va haciendo y que no sólo tiene implicaciones epistemológicas (de survol), sino existenciales. No se resigna a la reducción de sus dimensiones al mero uso instrumental de las mismas y, frente a la racionalidad dominante, plasmada en un estilo generalizado de pensamiento abstracto que pierde de vista la rica unidad de la vida y culmina en el cientificismo, se abre a todo el universo de la aisthesis que incluye la sensibilidad, las pasiones, los afectos ... En este horizonte de "promiscuidad" con el Ser y el mundo se halla también la razón ( $C f r$. Merleau-Ponty 1964, p. 292), no como posesión de un espectador desinteresado, sino como apertura a lo otro de sí del sujeto comprometido carnalmente. En esta línea, lucha contra la colonización de otras formas de pensar y actuar que han sido estigmatizadas; se hace cargo de sus orígenes y, por ello, va más allá de la razón constituida. Es capaz de dar cuenta de la riqueza de la existencia como movimiento doble que implica vivir en la razón y buscar la razón de vivir.

Algo semejante ha perseguido la razón zambraniana, "razón de amor integradora de la rica sustancia del mundo" (1989d, p. 68-69) ¿Cómo consigue serlo? Gracias a su participación amorosa en las esencias mundanas y las transmundanas; las primeras son fruto del desvalimiento que sentimos ante nuestra finitud y, las segundas del amor que nos impulsa a trascenderla.

Esta nueva razón se inspira en el logos del Manzanares al que se refería Ortega, ese que salvaba las circunstancias, esa razón revelada en las cosas pequeñas de la 
vida y el desvelamiento de éstas por el cauce de la razón. Ese humilde $\log _{o s}{ }^{23}$ llamado a suavizar la hybris de algunas filosofías, le abrió a Zambrano su propio camino filosófico, el que le llevó a la razón poética (Cfr. 1986, p. 123). Toma distancia del recurso orteguiano a nuevos principios, reclamando "algo que sea razón, pero más ancho", para que permita descubrir la integridad humana en todas sus dimensiones, incluido el centro de la realidad que es la profundidad cordial, el logos no dividido que siente mientras se siente. ${ }^{24}$ Media entre lo necesario y lo contingente confiando en que lo pasajero no perezca del todo. en el mismo sentido vital que detectamos en la fenomenología merleau-pontiana, e incluso como fuente o arché del que surge y por el que se desarrolla lo humano y el sentido del mundo ( $C f r$. Merleau-Ponty 1995, p. 86).

No nos parece, por consiguiente, como se ha dicho, que, a diferencia de Ortega, la filósofa no considere la vida como generadora de razón, sino como «fuente de sin-razón» (Cfr. Bundgärd 2000, p. 58), porque las pasiones, los afectos, etc. también forman parte de esa razón dilatada, que es, desde sus comienzos, una razón teórico-práctica. Con esto queremos decir que, aunque Zambrano recoge la herencia del maestro, la reformula estableciendo mediaciones entre los opuestos, acogiendo lo relegado, haciendo de la razón no sólo un instrumento que se sirve de los sentidos para dar nuevos sentidos, sino una apertura integradora de todo lo real en su concreción.

Esta nueva razón recupera lo que la razón abstracta olvida y la razón instrumental reprime. Se extiende incluso a la esperanza. La filósofa no propugna el irracionalismo, sino un racionalismo nuevo que recupere las razones del corazón, de las entrañas, que no son simples vísceras, sino esa dimensión carnal invisible desde fuera, pero reconocible por su importancia para la vida, pues constituyen la interioridad de la persona, esa que circula por los rizomas vivificando incluso cuando se padece. Por eso se ha dicho que, por un lado, la razón poética es tan modernista como lo son las vanguardias y el surrealismo, mientras que es postmoderna en tanto que corrige los excesos de la modernidad ( $C f r$. Bundgärd 2005, p. 58). Esto mismo podría predicarse de la fenomenología merleau-pontiana consciente de que el sentido siempre aparece cercado de sinsentido, de que el afán de grandeza de la conciencia va unido a sus desventuras.

La filosofía, así concebida, se guía por una razón unitaria y mediadora para comprender su resistencia, la realidad. Esta razón es vivida, sentida, porque su carácter poiético le hace actuar como fuerza generadora que profundiza hacia las raíces para después sacarlas a la luz e incluso, para tomar conciencia de que esa luz ya no proviene de la pura racionalidad, sino también de su participación en la aisthesis y en la poiesis.

\footnotetext{
23 Sobre la relación zambraniana con ese logos, López (2013, pp. 7-21).
}

${ }^{24}$ Zambrano, 1944, «Carta a Dieste», recogida en Moreno (2003, p. 102). 
La razón mediadora actúa como el círculo hermenéutico: recoge de cada singularidad alguna razón que le hace entrar en relación con las otras y, de este modo, con el sentido total que conforman. Así es como pasa de lo elemental a lo complejo para volver, más tarde, a aquél y enriquecerlo con las características estructurales que lo configuran como elemento.

Esta mediación de la razón toma en Merleau-Ponty la forma de una reflexión sobre lo pre-reflexivo que no desemboca en la absoluta coincidencia de ambos, sino en su interrelación. Por consiguiente, la filosofía no es un duplicado de la vida, sino «la instancia sin la cual la vida se disiparía en la ignorancia de sí y en el caos. Su función es afrontar todo lo que se le resiste, pues «huyendo de las dificultades se relajará de sus tareas» (Merleau-Ponty 1989, p. 56). Si renuncia a la búsqueda de sus orígenes, no echará raíces e incluso perderá el hábito de ser radical, de ir a la raíz de los problemas, que está en la base del ser humano.

La razón zambraniana es radical en el mismo sentido teórico -no teorético- y práctico, puesto que media entre el querer absolutamente y las contingencias de la vida temporal. No es una facultad innata, sino un proyecto crítico: exige la transformación de la razón dominante que, al considerarse absoluta, violenta.

En Horizonte del Liberalismo se perfila ya dicho proyecto. La autora piensa un liberalismo "nuevo", que tenga en cuenta a cada hombre. Rechaza la política económica del viejo liberalismo, porque sólo aplica la libertad que preconiza a unos pocos (Cfr. 1996a, p. 268). Para la autora, "política es reforma, creación, revolución siempre, por tanto: Lucha -conjunción- entre el individuo y la vida" (Ibídem, p. 204). La política zambraniana es revolucionaria, aunque no violenta, voluntad de transformación. Si la intuición es el conocimiento "revolucionario", debido a que da cuenta de lo que cambia, revolucionaria será la política que cuente con el tiempo; la otra, la que se considera atemporal será mera ideología.

El compromiso que se sigue de la fenomenología merleau-pontiana desemboca igualmente, en la defensa de un nuevo liberalismo incompatible con el capitalismo (Cfr. López 2010b). Rebate, el liberalismo convencional, con los mismos argumentos que Zambrano: describiendo las consecuencias de su racionalismo formalista y de la indeterminación de la libertad que propugna. Al igual que la autora, propone un nuevo liberalismo (1991, p. 329) del que no existen modelos, una tercera vía entre capitalismo y comunismo, una izquierda no comunista que aspira al humanismo que ninguno de los regímenes establecidos ha instaurado.

En 1930, en España, la joven Zambrano adelanta estas críticas y esta propuesta. Asombra la coincidencia del compromiso a la hora de salvar circunstancias tan diversas.

Como el fenomenólogo, busca una vía entre el liberalismo del orden, que no ha resuelto los problemas humanos y económicos, y el «descarnado comunismo, último producto del laboratorio racionalista que produjo en sus primeras manipulaciones el paradójico liberalismo» (1996a, p. 255). Ambos toman los elementos valio- 
sos del liberalismo y del comunismo, pero Zambrano parece considerar que la crítica y el diálogo no bastan para emprender su nueva vía y propugna una «tercera revolución» (Cfr. Moreno 1996, p. 163) no violenta, pero sí permanente, que recoja lo mejor de la revolución francesa: el reconocimiento de los derechos humanos, y lo más valioso de la de 1917: la igualdad económico-social. Desde nuestra perspectiva, la vía propuesta viene alumbrada por esa razón que se sabe menesterosa ante el ímpetu vital y, debido a ello, decide integrar las ricas dimensiones de la vida.

Años más tarde, Zambrano retomará las insuficiencias del individuo liberal distinguiéndolo de la persona en democracia, la cual es "nuestra íntima, única verdad" (2011c, p. 468). Ella es la verdadera interioridad sin máscaras sociales, aunque tampoco reducible a vida biológica, sino humana. En correlación con ella define la democracia, por no ser sólo un régimen político, ni una herencia cultural: "Democracia es la sociedad en la cual no sólo es permitido, sino exigido el ser persona" (Ibídem, p. 474). Nuevamente, la razón mediadora actúa adecuando la persona con la sociedad y a la inversa. Ahora bien, la persona, necesita crearse a sí misma y lo consigue gracias a la razón poiética que la hace renacer en el futuro, razón creadora que, al mismo tiempo, es la forma más fortalecedora de integración social.

\section{Conclusiones}

Bergson, Husserl, Merleau-Ponty y Zambrano fueron conscientemente asistemáticos, porque excavaban los cauces de la filosofía mientras la ejercitaban. Fundaron su posibilidad en la intuición, pero corrigiendo a Bergson desde una razón crítica transformada en telos. Para ellos, la intuición sólo podía ser el comienzo de una fenomenología de la misma en busca de su sentido. Su nueva manera de entender la re-flexión dilucidando sus implicaciones contribuirá a ello. En Zambrano y en Merleau-Ponty tal elucidación nunca será completa; de ahí que proclamen la necesidad de ampliar la razón para ir a la raíz y profundizar en lo invisible. Mientras Merleau-Ponty continúa, para ello, la fenomenología genética de Husserl, Zambrano sentencia que Husserl abandona el lado más vivificante de la significación intuitiva al caer en el logicismo de la misma y al analizar lo percibido como si fuera un acto mental. ${ }^{25}$ Merleau-Ponty le dirigió análogas críticas. ${ }^{26}$ A pesar de ello, la impronta husserliana de esa intuición, que no sólo es sensible, sino también intelectual27, perdura en sus filosofías.

\footnotetext{
25 (Cfr. Zambrano 1966, p. 117). La acusación de "logicismo" debe ser matizada: en 1929, Husserl nos presenta una lógica trascendental que desarrolla el lado subjetivo del sentido de la lógica evitando el psicologismo.

26 En Merleau-Ponty, como en Husserl, la percepción es un acto, pero, a diferencia de él, no es un acto de la conciencia; con ella, no conocemos objetos de carne y hueso (Husserl), sino existencias.

27 Ortega ha estudiado la intuición intelectual zambraniana en su relación con el noûs de Aristóteles, como síntesis de razón discursiva e intuitiva (Cfr. 2005, p.172).
} 
Ambos reaccionan como él y como Bergson, contra el cientificismo y el racionalismo abstracto que pierden la realidad cuando la cuantifican. Reivindican una razón en vías de hacerse e integradora, inseparable de la ética, del deber ser y de la acción.

La intuición bergsoniana, así como la razón intuitiva de Husserl, reformulada en la correlación intencional entre nóesis y nóema, deviene, en Merleau-Ponty, razón que rehabilita lo sensible y se vivifica con él (Cfr. López 2013, pp. 83 y ss.), y en Zambrano, razón mediadora. Como para Bergson y la fenomenología, ésta es primordialmente intuitiva; luego re-flexiona sobre lo intuido y sobre sí misma de un modo no impositivo, porque la razón toca y se derrama por lo que va a su encuentro y no es prerrogativa del sujeto ( $C f r$. 2011, p. 140); tampoco lo es para MerleauPonty que se distancia del sujeto trascendental de Husserl.

Muy cerca del logos tácito merleau-pontiano, que rehabilita lo sensible, Zambrano irá explicitando el logos sumergido que clama desde una razón más ancha que la discursiva: el sentir de la vida que se entrega en un lenguaje indirecto y simbólico. Se irá percatando, como el fenomenólogo, de que el origen de la reflexión es lo pre-reflexivo, lo que pasivamente se nos revela y profundamente nos afecta.

Frente al abstracto idealismo y al estrecho positivismo ${ }^{28}$, la intuición del sentir originario presagia los claros en medio del misterio en los que, ocasionalmente, es sorprendida la vida que sigue esa lógica del sentir para vivir, la vida en la que coexisten la acción y la pasión entre las que opera la razón mediadora buscando en las entrañas el claro en el que pueda despejarse el ser recóndito del que mana la vida. Lo que Zambrano está reivindicando es "una nueva concepción de la claridad, una atención a las formas discontinuas de la luz y del tiempo", que fue iniciada por "la llamada psicología de lo profundo. $\mathrm{Y}$ así también en la fenomenología de Husserl". ${ }^{29} \mathrm{Ni}$ claridad que ciegue y anule la búsqueda, ni completa oscuridad. Eso es el saber zambraniano, distinto del conocimiento que, en Ortega, siempre es $a$ posteriori.

La razón poética zambraniana se suma a la lucha merleau-pontiana contra los opuestos y se adhiere al postulado fenomenológico de la unidad de la razón teórico-práctica y a la relación de lo universal con lo singular, del ser con las apariencias (filosofía y poesía). En este sentido, expresa que debemos a Husserl el redescubrimiento de la unidad del objeto, a pesar de que las pretensiones de totalidad de

\footnotetext{
28 Zambrano considera la la fenomenología de Husserl como "la forma más extrema de positivismo" (1990, p. 11), quizás porque interpreta presurosamente su máxima, "a las cosas mismas" o porque no ha profundizado en Ideas I. Merleau-Ponty, en cambio, dice que la fenomenología no es "ni un materialismo, ni una filosofía del espíritu" (1960, p. 208), sino una crítica de ambas idealizaciones.

29 (1989b, p. 26). La autora se refiere a Freud, concretamente a su crítica de la psicología superficial, así como a la psicología fenomenológica que, previamente, ha criticado al psicologismo. Echa en falta en ambos una metafísica crítica de la precedente. Esta es la tarea que asumió Bergson.
} 
su fenomenología hayan coartado la exploración metafísica la experiencia humana (Cfr. 1989b, p. 26). Reconoce su genialidad, unida a sus infatigables investigaciones, su audacia y su humildad, pero sigue viéndolo como un cartesiano sin detenerse, por ejemplo, a analizar las diferencias entre su epojé y la duda. No obstante, valora que ambas nos inviten a practicar la docta ignorancia y a encontrar la verdad en lugar de abdicar de ella (Cfr. Ibídem, pp. 211, 215).

En su busca, Zambrano desciende a los ínferos para abrirlos a la aurora, rescatando las entrañas, recuperando el sentir originario que también forma parte del alma y de la racionalidad que se hace cargo de ella. Este desentrañar racional es otro modo de pensar; ejerce una transformación, una poiesis que da cauce y expresión a lo entrañable; por eso, la razón que nos guía desde la oscuridad a la luz y de ésta a aquélla es también razón poética.

Como para Merleau-Ponty, filosofar no consiste únicamente en vivir, sino que exige despertarse y tomar partido. No obstante, son conscientes de que este acto de libertad ni es absoluto, ni adviene ex nihilo: se genera en la vida, mezcla de actividad y de pasividad, de despertares y sueños. Inaugura una manera de pensar en espiral que -como ocurre con la hiperdialéctica merleau-pontiana-se adentra en lo invisible de lo visible dotándolo de dimensiones hacia el exterior. Para ello, es necesaria esa razón mediadora que aprehende la realidad en su dinámica, que enseña a ver más de lo que se ve. Como en Merleau-Ponty, la razón activa-pasiva culmina en la palabra. Su esencia es revelar manifestando; por eso, es preciso renovar el lenguaje e incluso el modo de hacer filosofía para que ésta sea creadora.

Zambrano conecta abiertamente con la fenomenología de este autor, con la de Scheler, Heidegger, Sartre, Lévinas, porque reactivan esa potencialidad filosófica de describir lo que aparece para descifrar lo que no se manifiesta a la conciencia, pero que es lo más originario y vital.

La razón merleau-pontiana, la zambraniana no son razones de medianías, temerosas de adentrarse en lo no transitido, sino razones transformadoras, conscientes de sus máscaras históricas y de su caída; estas razones han perdido su soberbia, pero no sus aspiraciones liberadoras y trascendentes, las mismas que mueven a la filosofía, que sólo puede ser crítica y auto-crítica.

En el siglo XXI, seguimos necesitando esta renovada razón que medie entre los aparentes contrarios que nos integran, una razón que salven las diferencias y los problemas sin sobrevolarlos, "ahondando, penetrando en el subsuelo donde las raíces se entrecruzan y confunden" 30 , como siempre ha hecho la verdadera filosofía, esa que piensa y crea con todas las fuerzas la riqueza de lo real, una razón ampliada -no especializada- que integra los saberes en la vida y, haciéndolo, repercute en ella.

30 (Zambrano 1996a, p. 264). Merleau-Ponty siempre intento evitar la filosofía de survol (sobrevuelo). 


\section{Referencias bibliográficas}

BALzA, I. (2000): Tiempo y escritura en María Zambrano. Bilbao, Iralka.

Bergson, H. (1984a, [1934]): «La pensée et le mouvant», en Oeuvres. Paris, Gallimard, pp. 1251-1617.

Bergson, H. (1984b, [1903]): «Introduction à la metaphysique», Oeuvres. pp. 1392-1432.

Bergson, H. (1984c, [1907]): «L'évolution créatrice», en Oeuvres, pp. 487-813.

Bergson, H. (1984d, [1896]) : «Matière et mémoire», en Oeuvres. pp. 161-382.

Bergson, H. (1992, [1922]): Durée et simultanéité, Paris, PUF.

Bundgärd, A. (2000): Más allá de la filosofía. Sobre el pensamiento filosófico-místico de María Zambrano. Madrid, Trotta.

BundgäRD, A. (2005): «La razón poética: ética y estética», en P. Cerezo, (ed.) Filosofía y literatura. María Zambrano. Sevilla, Fundación José M. Lara.

BundGÄRD, A. (2009): Un compromiso apasionado. María Zambrano: una intelectual al servicio del pueblo (1928-1939). Madrid, Trotta.

Caeymaex. F. (2005): Sartre, Merleau-Ponty, Bergson. Les phénoménologies existentialistes et leur héritage bergsonienne. Paris, Olms.

ConILL, J. (1991): «La transformación de la fenomenología en Ortega y Zubiri», en San Martín, J. Ortega y la fenomenología. Madrid, Uned, pp. 296-312.

Conill, J. (2005): «Die Phänomenologie bei Zubiri", in San Martín, J. Phänomenologie in Spanien. Würtzburg, Koenigshausen \& Neumann, pp. 43-56.

Husserl, E. (1984a), [1900119132]): Logische Untersuchungen. Husserliana $X I X / 1$, The Hague, M. Nijhoff.

Husserl, E. (1984b): Logische Untersuchungen. Husserliana XIX/2, The Hague, M. Nijhoff.

Husserl, E. (1973, [1907]): Die Idee der Phänomenologie. Fünf Vorlesungen. Husserliana II. Den Haag, M. Nijhoff.

Husserl, E. (1976, [1913]): Ideen zu einer reinen Phänomenologie und phänomenologischen Philosophie. Erstes Buch. Husserliana III/1. Den Haag, M.

Husserl, E. (1991, [1931]): Cartesianische Meditationen und Pariser Vorträge. Husserliana I, Den Haag, M. Nijhoff.

LÉvinas, E. (1991): Entre nous. Paris, Bernat Grasset.

Lizaola, J. (2008): Lo sagrado en el pensamiento de María Zambrano. México, Ed. Coyoacán.

LóPEZ SÁENZ, Ma C. (2003): «El sentido de la Aisthesis en Merleau-Ponty», en Santos, J. M. Alves, P. y Barata, A. (eds.) A Fenomenologia Hoje, en, Phainomenon, pp. 299-311.

López SÁenz, M ${ }^{a}$ C. (2007d): «De la sensibilidad a la inteligibilidad. Rehabilitación del sentir en M. Merleau-Ponty», Phainomenon. Revista de fenomenología, $\mathrm{n}^{\circ}$ 14, pp. 171-193. 
López SÁenz, Ma C. (2010a): «Razones estéticas. Zambrano y Merleau-Ponty», en Boletín de estudios de filosofia y cultura M. Mindán. Pensamiento español contemporáneo: La fenomenología en España, vol. V, pp, 205-232. http://www.fundacionmindanmanero.org/publicaciones.html

López SÁEnz, Ma C. (2010b): «Fenomenología y marxismo. El compromiso político de Merleau-Ponty», en Daimon. Revista de Filosofía, 51, pp. 103-121.

López SÁenz, Ma C. (2012a): «Universalidad existencial (M. Merleau-Ponty) frente a relativismo cultural (C. Lévi-Strauss», en López, $\mathrm{M}^{\mathrm{a}} \mathrm{C}$. y Díaz, J.M. Racionalidad y relativismo. En el laberinto de la diversidad. Madrid, Biblioteca Nueva, pp.19-108.

López SÁenz, Ma C. (2012b): Corrientes actuales de Filosofía I. En-clave fenomenológica. Madrid, Dykinson.

López SÁenz, Ma C. (2013): Dos filosofias del sentir. M. Merleau-Ponty y M. Zambrano. Saarbrücken, AV. Akademikerverlag.

LÓPEz SÁenz, Ma C. (1964): Le Visible et l'Invisible. Paris, Gallimard.

López SÁenz, Ma C. (1979), (1945): Phénoménologie de la perception. Paris, Gallimard.

López SÁenz, Ma C. (1989, [1934]): Le primat de la perception et ses conséquences philosophiques. Paris, Cynara.

López SÁenz, Ma C. (1995): La Nature. Notes de Cours du Collège de France. Paris, Seuil.

López SÁenz, Ma C. (2003): L’Institution. La passivité. Notes de Cours au Collège de France (1954-1955), Paris, Belin.

López SÁEnz, Ma C. (1991, [1955]): Les aventures de la dialectique. Paris, Gallimard, col. "Idées".

Merleau-Ponty, M. (1960): Signes. Paris, Gallimard.

Merleau-Ponty, M. (1964): Le Visible et l'Invisible. Paris, Gallimard.

Merleau-Ponty, M. (1979, [1945]): Phénoménologie de la perception. Paris, Gallimard.

Merleau-Ponty, M. (1989, [1934]): Le primat de la perception et ses conséquences philosophiques. Paris, Cynara.

Merleau-Ponty, M. (1995): La Nature. Notes de Cours du Collège de France. Paris, Seuil.

Merleau-Ponty, M. (1991, [1955]): Les aventures de la dialectique. Paris, Gallimard, col. "Idées".

Moreno Sanz, J. (1996): «Estudio introductorio: La política desde el envés histórico-vital: Historia trágica de la esperanza y sus utopías», en M. Zambrano (1996a), pp. 9-194.

Moreno Sanz, J. (2003): La razón en la sombra. Antología crítica. María Zambrano. Madrid, Siruela. 
Moreno Sanz, J. (2008a): El logos oscuro: tragedia, mística y filosofía en María Zambrano. Vol. II. Madrid, Verbum.

Moreno Sanz, J. (2008b): El logos oscuro: tragedia, mística y filosofía en María Zambrano. Vol. IV. Madrid, Verbum, 2008, p. 379.

OrtegA, J.F. (2005): «Vigencia del pensamiento de M. Zambrano», en Pensamiento y palabra. Valladolid, Junta de Castilla y León, pp. 169-184.

Ortega y Gasset, J. (1981), (1914): Meditaciones del Quijote. Madrid, Alianza.

Pintor Ramos, A. (1991): «Zubiri y los inicios de la fenomenología en España», en

San Martín, J. Ortega y la fenomenología, pp. 285-296.

SAn MARTín, J. (2012): La fenomenología de Ortega y Gasset. Madrid, Biblioteca Nueva.

TEJADA, R. (ed.) (2011): M. Zambrano. Escritos sobre Ortega. Madrid, Trotta.

Waldenfels, B. (1997): De Husserl a Derrida. Introducción a la fenomenología. Barcelona, Paidòs.

Zambrano, M. (1996a, [1930]): Horizonte del liberalismo. Madrid, Morata.

ZAmbrano, M. (1989d, [1937]): «La guerra de Antonio Machado», en Senderos.

Barcelona, Anthropos, pp. 60-70.

ZAmBrano, M. (1995, [1943]): La confesión: género literario. Madrid, Siruela.

Zambrano, M. (19922, [1944]): El pensamiento vivo de Séneca. Madrid, Cátedra.

ZAmbrano, M. (1994, [1950]): «La actitud filosófica», en M ${ }^{\mathrm{a}}$ F. Santiago (edra.) La

llama sobre el agua. Alicante, ed. Aitana, pp. 25-30.

ZAMBRANo, M. (20086, [1950]): Hacia un saber sobre el alma. Madrid, Alianza.

ZAMBrANo, M. (1966): «Inédito M129», en Moreno, 2003, pp. 114-125.

Zambrano, M. (1975): «Miguel de Molinos, reaparecido», en Ínsula, n 338, Enero.

Zambrano, M. (1986, [1983]): Aurora. Madrid, Turner.

Zambrano, M. (1987a): «A modo de autobiografía», en Anthropos. María Zambrano, no 70-71, pp. 69-73.

Zambrano, M. (1987b): «Del método en filosofía”, en Ibídem, pp. 120-124.

ZAMBRANO, M. (1987c): «El tiempo y la verdad”, en Ibídem, pp. 108-112.

Zambrano, M. (1989b): Notas de un método, Barcelona, Mondadori.

Zambrano, M. (1989c): Para una historia de la piedad. Málaga, Torre de las Palomas.

ZAMBRAno, M. (1990): Los bienaventurados. Madrid, Siruela.

ZAmbrano, M. (2011a, [1965]): El sueño creador, en Obras Completas III. Barcelona, Galaxia Gutenberg, pp.1014-1100.

ZAMBRANo, M. (2011b, [1992]): Los sueños y el tiempo, en Ibídem, pp. 845-958. Zambrano, M. (2011c, [1958]): Persona y democracia, en Ibídem, pp. 379-504. ZAmBrano, M. (2005, [1956]): «Dos fragmentos acerca del pensar», Aurora. Papeles del “Seminario María Zambrano”, n 7, pp. 95-97. 
Zambrano, M. (2011d, [1977]): Claros del Bosque. Madrid, Cátedra.

Ma Carmen López Saénz.

Facultad de Filosofía

Universidad Nacional de Educación a Distancia

clopez@fsof.uned.es 